\title{
FACTORS ASSOCIATED WITH DELAYED AMBULANCE RESPONSE TIME IN HOSPITAL UNIVERSITI SAINS MALAYSIA, KUBANG KERIAN, KELANTAN
}

\author{
Teo Sin $\mathrm{Di}^{1}$, Mohd Boniami Yazid ${ }^{2}$, Mohd Shaharudin Shah Che Hamzah', Tuan Hairulnizam Tuan \\ Kamauzaman ${ }^{2}$, Normalinda Yaacob² and Nik Hisamuddin Nik Ab. Rahman ${ }^{3}$ \\ ${ }^{1}$ Department of Emergency Medicine, Hospital Sultanah Aminah Johor Bahru,80000 Johor Bahru, Johor, \\ Malaysia. \\ ${ }^{2}$ Department of Emergency Medicine, School of Medical Science, Universiti Sains Malaysia, Kubang \\ Kerian, 16150 Kelantan, Malaysia. \\ ${ }^{3}$ Hospital Universiti Sains Malaysia, Kubang Kerian, 16150 Kelantan, Malaysia.
}

Corresponding author: Mohd Boniami Bin Yazid

E-mail: boniami@usm.my

\begin{abstract}
Ambulance response time is one of the key performance of ambulances services. The objective of this study is to determine the factors associated with delayed ambulance response time in Hospital Universiti Sains Malaysia (HUSM). This was a cross sectional study conducted in Department of Emergency Medicine, Hospital Universiti Sains Malaysia (EDHUSM) between January 2016 to January 2017. A total of 300 ambulance calls were included in our analysis. Data were collected by ambulance paramedic using validated ambulance form. All ambulance forms with missing data were excluded from this study. Of the 300 ambulance calls within the study periods, 254 cases (84.7\%) were determined to have delayed ambulance response time. Current ambulance response time is 14 minutes with interquartile range of 5 minutes. Factors which showed significant association delayed ambulance response time include distance from hospital, location, type of emergency and ambulance mechanism. The odd of delayed ambulance response time by every increase in distance unit was 1.59 (95\% Cl, 1.37 to 1.85). For location type, the odd of delayed ambulance response time for public location as compared to road was 0.13 (95\% Cl, 0.04 to 0.45). For ambulance mechanism, the odd of delayed ambulance response time for beacon type as compared to siren type was 0.22 (95\% Cl, 0.01 to 0.69). Further intervention should be initiated based on our findings to improve current ambulance response time.
\end{abstract}

Keywords: delayed ambulance response time, associated factors, emergency medical service.

\section{INTRODUCTION}

Ambulance service is one of the components of prehospital service. Response time is crucial in managing medical and trauma emergencies such as cardiac arrest, airway obstruction, severe haemorrhage, severe chest or head injury ${ }^{1}$. This was proven particularly for out-of-hospitalcardiac arrest ${ }^{2}$ and trauma victims in urban settings ${ }^{3}$. The effectiveness of ambulance service is characterised by the following two measures of performance: response time and service time ${ }^{4}$. The shorter the time intervals, the more effective the system ${ }^{4}$. Ambulance response time (ART) is defined as the period between emergency call received and ambulance arrival at scene ${ }^{5}$. Current recommendation of ambulance response time in response to medical emergencies is within 8 minutes for at least $90 \%$ ambulance calls ${ }^{6}$. This response time had evolved into a guideline that had been incorporated into operating agreements for many emergency medical service providers ${ }^{7}$. At present, ambulance services in Malaysia are provided countrywide by governmental and nongovernment bodies ${ }^{8}$.

Government provisions is under control of Ministry of Health (MOH), Ministry of Education (MOE) and Civil Defence (CD) whereas non-governmental bodies are private sectors such as St John's
Ambulance, Red Crescent and some at private hospitals ${ }^{8}$. Most government ambulances are based in hospital facilities. In EDHUSM, ambulance services are run under hospital based system whereby all ambulances are located in hospital compound (near Department of Emergency Medicine) ${ }^{10}$. Ambulances will be despatched to scene site as soon as possible once emergency calls were received. Since January 2005, an Emergency Medical Dispatcher (EMD) squad was launched in EDHUSM ${ }^{10}$. This is a dedicated unit which consist of ambulance crews who were trained under EMD course that was modified from Emergency Medical Services Authority of California to become EMD to manage all ambulance calls in EDHUSM ${ }^{10}$. These EMD personnel are hospital attendants who had successfully passed their EMD training and managed all ambulance calls which includes call taking and responding to ambulance calls ${ }^{10}$. In addition to this EMD team, a team called Rescue 991 under Angkatan Pertahanan Awam Malaysia (APM) (specialised government body established to assist disaster and emergency event) were located in EDHUSM since 2000.

Their main purpose was to extend social work services to public including ambulance services ${ }^{11}$. This is a unique team which only exists in EDHUSM. A study regarding ART in Kelantan was conducted in 2004 by Shaharudin et $\mathrm{al}^{10}$ concluded that ART 
in EDHUSM Kelantan was 15.2 minutes. Only $40 \%$ of the total ambulance call in EDHUSM responded within 8 minutes. This is far from international standard of criteria of 8 minutes or less in at least $90 \%$ of ambulance calls. Factors that needs to be considered to achieve the international standard includes type of ambulance service, sociodemographic patterns, geographical differences and public behavioural influences toward good behavioural practices ${ }^{9,10}$. The objective of this study was to determine factors that contribute to delay ambulance response time.

\section{METHODOLOGY}

Setting, study design, sample size determination

This was a cross sectional study conducted in HUSM between January 2016 to January 2017. The average ambulance call received by EDHUSM was 600 to 700 per year ${ }^{10}$. In order to determine the sample size for this study, data on three factors that were determined to be significant in affecting ambulance response time based on previous study ${ }^{12}$ were used in calculation. Alpha level of 0.05 and statistical power of 0.8 were used. A sample size of 300 including $30 \%$ drop-out rate was determined.

\section{Data collection and processing}

All data were collected by ambulance paramedics of HUSM using a standardized form 'Borang Sela Masa Tindak Balas Ambulans'. These ambulance paramedics were enrolled in the study based on voluntary basis. They were briefed regarding the purpose of the study using 'Borang Maklumat Kajian' and a written consent form 'Borang Keizinan' were given to them. Only those consented ambulance paramedics were involved in the study. Ambulance form with missing data were excluded in the study. All ambulance forms were completed by paramedics after attending each ambulance calls during the study periods. The ambulance forms that were used in this study were validated earlier ${ }^{23}$. The ambulance forms consist of 6 sections: (1) Call receiver and biography of ambulance team (2) Call time (3) Patients information (4) Route to location (5) Ambulance specification (6) Geographical factor. Call receiver were EMD, medical assistant, staff nurse, doctor or others. Biography data of ambulance team consist of their working experiences, highest academic achievement, age and gender. Call time were recorded as international time and include call receiving time, team activation time, ambulance despatch time and scene arrival time. Ambulance response time was measured as the time between scene arrival time and call received time. Patients information encompasses zone that they were triaged to upon arrival to hospital (critical-red, semi criticalyellow or noncritical-green) and the location of incident (road, housing area, public area, working place or others). Route to location include congested or smooth (non-congested) route and these parameters were determined subjectively by ambulance driver. Ambulance specification were ambulance brands (Toyota, Mercedes, Aveco, Ford), ambulance type (A, B, C) and ambulance warning system (siren, beacon, public announcement system). Geographical factors consist of precision location, distance from hospital to location and other factors (such as flood, landslide, or heavy rain). Precise location was defined as the ambulance arrived at the correct location with the address that were given by the caller.

\section{Statistical Analysis}

Statistical analysis was performed using IBM SPSS version 22. $\mathrm{P}$ value $<0.05$ was considered statistically significant. Categorical variables were summarised using percentages and compared using Chi-square test. Mean values of numerical variables between two groups were compared by student t-test. Logistic regression was used to identify factors associated with delayed ambulance response time and to estimate odds ratio (OR) and $95 \%$ confidence interval $(\mathrm{Cl})$ for the association between variables. Variables with $p$ values $<0.25$ were introduced in multivariate logistic regression model. A manual backward stepwise approach was used to remove non-significant variables; only variables with $p<0.05$ were retained in the final model.

\section{Ethical Issues}

Only the consented ambulance paramedics were involved in this study. This study had obtained ethical approval from The Human Research Ethics Committee of USM [USM/JEPeM/15110497].

\section{RESULTS}

\section{Simple Logistic Regression on Factors Associated with Delayed Ambulance Response Time}

The factors which showed significant association with delayed ambulance response time include distance $(p<0.01)$, location type $(p<0.01)$ and ambulance mechanism $(p<0.01)$. The odds of delayed ambulance response time by every increase in distance unit was $1.59(95 \% \mathrm{Cl}, 1.37$ to 1.85). For location type, the odds of delayed ambulance response time for public location as compared to that of road was $0.13(95 \% \mathrm{Cl}, 0.04$ to 0.45 ). For ambulance mechanism, the odds of delayed ambulance response time for beacon type as compared to that of the siren type was 0.22 ( $95 \% \mathrm{Cl}, 0.01$ to 0.69 ).

Analyses of the associated factors for delayed ambulance response time by simple logistic regression is summarized in Table 2 . 
Table 2: Associated factors of delayed ambulance response time by Simple Logistic Regression model

\begin{tabular}{|c|c|c|c|c|}
\hline Variables & $\begin{array}{l}\text { Regression } \\
\text { coefficient (b) }\end{array}$ & $\begin{array}{c}\text { Crude Odds Ratio } \\
(95 \% \mathrm{Cl})\end{array}$ & $\begin{array}{l}\text { Wald } \\
\text { statistic }\end{array}$ & $\mathrm{p}$-value \\
\hline \multicolumn{5}{|l|}{ Geographical } \\
\hline Distance & 0.46 & $1.59(1.37,1.85)$ & 0.00 & 0.000 \\
\hline \multicolumn{5}{|l|}{ Location type } \\
\hline Road & - & - & - & - \\
\hline Housing Area & 0.51 & $1.66(0.73,3.79)$ & 1.46 & 0.227 \\
\hline Public & -2.01 & $0.13(0.04,0.45)$ & 10.46 & 0.001 \\
\hline Workplace & -0.47 & $0.63(0.07,5.98)$ & 0.17 & 0.683 \\
\hline Others & -0.50 & $0.61(0.23,1.56)$ & 1.07 & 0.300 \\
\hline \multicolumn{5}{|l|}{ Precision of location } \\
\hline No & 19.51 & $2.98 \times 10^{8}(0.00,-)$ & 0.00 & 0.998 \\
\hline Yes & - & - & - & - \\
\hline \multicolumn{5}{|l|}{ Mechanical } \\
\hline \multicolumn{5}{|l|}{ Ambulance Brand } \\
\hline Toyota & - & - & - & - \\
\hline Mercedes & 0.418 & $1.52(0.19,12.32)$ & 0.153 & 0.695 \\
\hline \multicolumn{5}{|l|}{ Ambulance Category } \\
\hline A & -23.03 & $0.00(0.00,-)$ & 0.00 & 0.999 \\
\hline B & 0.02 & $1.023(0.47,2.22)$ & 0.00 & 0.953 \\
\hline C & - & - & - & - \\
\hline \multicolumn{5}{|c|}{ Ambulance Warning System } \\
\hline Siren & - & - & - & - \\
\hline Beacon & -1.50 & $0.22(0.01,0.69)$ & 6.71 & 0.010 \\
\hline Siren, beacon & -0.20 & $0.82(0.35,1.92)$ & 0.20 & 0.652 \\
\hline Siren, beacon, PA & 19.14 & $2.05 \times 10^{8}(0.00,-)$ & 0.00 & 0.999 \\
\hline \multicolumn{5}{|l|}{ Temporal } \\
\hline \multicolumn{5}{|l|}{ Route } \\
\hline Smooth & - & - & - & - \\
\hline Congested & 1.30 & $3.67(1.49,9.06)$ & 7.96 & 0.005 \\
\hline
\end{tabular}

Multiple Logistic Regression on Factor Associated with Delayed Ambulance Response Time

Analyses of the significant associated factors for delayed ambulance response time by multiple logistic regressions was shown in Table 3. Multiple Logistic Regression ( $p<0.05$ was significant); The goodness of fit of the model was checked using
Hosmer-Lemeshow test. The result gives no evidence of lack of fit of the model. According to the analysis, there was only the increment of distance showed significant association with the delayed ambulance response. Hence, the three associated factors for delayed ambulance delayed likely to be independent association than group factor. 
Table 3: Associated factors of delayed ambulance response time by Multiple Logistic Regressions model

\begin{tabular}{lcccc}
\hline Variables & $\begin{array}{c}\text { Regression } \\
\text { coefficient (b) }\end{array}$ & $\begin{array}{c}\text { Adjusted Odd } \\
\text { Ratio }(95 \% \mathrm{Cl})\end{array}$ & $\begin{array}{c}\text { Wald } \\
\text { statistic }\end{array}$ & p-value \\
\hline $\begin{array}{c}\text { Geographical } \\
\text { Distance }\end{array}$ & 0.417 & $1.52(1.30,1.77)$ & 27.73 & 0.000 \\
& & & & \\
Location type & - & - & - & - \\
$\quad$ Road & 0.81 & $2.25(0.85,5.93)$ & 2.67 & 0.102 \\
Housing Area & -0.99 & $0.37(0.08,1.84)$ & 1.47 & 0.225 \\
Public & 0.86 & $2.37(0.11,53.06)$ & 0.29 & 0.588 \\
Working place & 0.36 & $1.43(0.43,4.82)$ & 0.33 & 0.567 \\
$\quad$ Others & & &
\end{tabular}

Mechanical

Ambulance Warning System

Siren

Beacon

$0.34(0.08,1.53)$

1.98

0.159

Siren, beacon

0.03

Siren, beacon, PA

18.56

$1.03(0.37,2.88)$

0.03

0.954

$1.15 \times 10^{8}(0.00,-)$

0.00

0.999

Temporal

Route

Smooth

Congested

0.791

$2.21(0.76,6.37)$

2.136

0.144

\section{DISCUSSIONS}

\section{Key factors affecting ambulance response time}

ART is the measurement of ambulance performances. It consists of call processing time, team assembling time and travelling time taken to the scene ${ }^{13}$. These time intervals had shown improvement compared to previous study ${ }^{11}$. Based on the current study, the mean ambulance response time in HUSM was 14.1 minutes and $14.3 \%$ of ambulance calls respond within 8 minutes. This result shows that there was $7.2 \%$ improvement of mean ambulance response time from 15.2 minutes $^{11}$ to 14.1 minutes. The improvement in ART due to annual assessment such as pre-schedule training and short courses pertaining to management of ambulance call that were carried out among the EMD personnel by the department. However, current ambulance response time is still far from international standard criteria which is 8 minutes or less in at least $90 \%$ of ambulance calls.

In our study, we investigated both geographical and mechanical factors that contributed to the delayed ART. Among the geographical factors, distance and location were associated with delayed ambulance response time. The percentage of ART within 8 minutes were higher, which was $7 \%$ if distances were within $8 \mathrm{~km}$, in comparison to those that responded beyond the $8 \mathrm{~km}$ radius $(0.7 \%)$. This is in agreement with Breen et al (2000) who reported that ambulance calls responding to emergencies more than five miles away from nearest ambulance station had less than $5 \%$ likelihood of ability to respond within 8 minutes ${ }^{1}$. The median distance of response by HUSM's ambulances was $7.8 \mathrm{~km}$. This had exceeded the requirement range as per department standard operating policy which is within $6 \mathrm{~km}$ radius ${ }^{24}$ from HUSM. The reason for this is due to lack of manned vehicles from nearby ambulance base station, which is also one of the identified factor that influenced response time performance in Breen et al ${ }^{1}$. Paramedic who were involved in ambulance calls from this ambulance base station were actually those who involve in other daily work in their hospitals. Therefore, EMD program should be implemented in order to create a dedicated emergency ambulance team to manage ambulance calls. 
From this study, $65.4 \%$ of ambulance calls cases that responded were non-life threatening. Prioritised dispatching (give priority to those cases needing urgent paramedic care or urgent transport to hospital) has been shown to be an effective strategy for use in ambulance service ${ }^{14}$. Ambulance responses in less than or equal to 8 minutes were higher and the odds of dying was $1.4 \%$ less by using priority dispatch system for ambulance deployment ${ }^{15}$.

Another geographical factor that contributed to delayed ambulance response time was the type of location. Among the studied locations, ART to public places (schools, market, commercial places) were longer compared to other locations. This might be due to bystander interference and physical barriers (stairs, elevators) causing difficult accessibility to the scene site. These two factors were among the factors that affect the interval between ambulance arrival at scene and ambulance personnel arrival to patient ${ }^{16}$. Incident that occur at high rise building also contribute to delay response time. This is due to the vertical response time (the need to climb stairs or board the elevators) needed for paramedic team to reach the patient's side ${ }^{17}$.

Lateef et al (2000) reported that the problems encountered in high rise building were multiple stops of the elevator for use by the public, preset elevator stops, all elevators being in use, lack of directions, inadequate space in the stairwell or the elevator prohibiting use of a stretcher ${ }^{18}$. Therefore, building structures which take into consideration of emergency access should be enforceable in all high-rise buildings. Not only the ambulance respond time can be improved, the safety of paramedics and patients also can be ensured.

In this study, we observed that usage of only beacon light was associated with delayed ambulance response time. The chance of delayed ambulance response time when using beacon light was $22 \%$. This contradicts with Brown et al (2000) who reported lights and siren(L\&S) reduce ambulance response time by 1 minutes 46 seconds, a statistically significant time saving. However, this time saving is only clinically relevant in very few cases and it requires a larger multi-centre L\&S trial to address this issue ${ }^{19}$. A study conducted by Brien et al (1998) also showed that L\&S shortens transport-time but the time saved was not associated with immediately apparent clinical significance. In addition to this, L\&S was reported as direct cause of emergency vehicles crashes $^{21}$, hence the time saving with L\&S should be balanced against the risk associated with its usage.

\section{Limitation}

Samples data were completed by ambulance paramedics who responded to ambulance calls, therefore bias and incomplete documentation were unavoidable.

\section{CONCLUSIONS}

Current ambulance response time in Hospital Universiti Sains Malaysia was 14.1 minutes. This showed that we still have not reach the international standard for ambulance response time. Distance, location type and ambulance mechanism showed significant association with delayed ambulance response time. Among these factors, distance was found to have the largest effect.

\section{ACKNOWLEDGEMENT}

This research is funded by short term grant (304/PPSP/61313191) under School of Medical Sciences, Universiti Sains Malaysia. We would like to thank the experts panel who were involved in the validation of the ambulance form.

Special thanks to staffs of EDHUSM; Encik Mohd Zamri Yusoff, Encik Muhammad Hazwan Bin Mohammad Zawawi and Encik Hairil Izham Bin Azlan, without whom the data would not be available.

\section{REFERENCES}

1. Breen N, Woods J, Bury G, Murphy AW, Brazier $\mathrm{H}$. A national census of ambulance response times to emergency calls in Ireland. Emergency Medicine Journal 2000 Nov 1;17(6):392-5.

2. Valenzuela TD, Roe DJ, Nichol G, Clark LL, Spaite DW, Hardman RG. Outcomes of rapid defibrillation by security officers after cardiac arrest in casinos. New England Journal of Medicine 2000 Oct 26;343(17):1206-9.

3. Feero S, Hedges JR, Simmons E, Irwin L. Does out-of-hospital EMS time affect trauma survival? The American journal of emergency medicine 1995 Mar 1;13(2):133-5.

4. Singh VK, Chandran AJ, Dey BR. Operation research for estimation of ambulance requirement in a hospital. Computer methods and programs in biomedicine. 1990 Oct 1;33(2):59-63.

5. Noble,J.H, et al . Emergency Medical Services. Behavioral and Planning Perspectives. Behavioral Publication, 347.

6. Pons PT, Markovchick VJ. Eight minutes or less: does the ambulance response time guideline impact trauma patient outcome? The Journal of emergency medicine. 2002 Jul 1;23(1):43-8. 
7. Mullie A, Van Hoeyweghen R, Quets A, Cerebral Resuscitation Study Group. Influence of time intervals on outcome of CPR. Resuscitation. 1989 Jan 1;17: S23-33.

8. Hisamuddin NN, Hamzah MS, Holliman CJ. Prehospital emergency medical services in Malaysia. The Journal of emergency medicine 2007 May 31;32(4):415-21.

9. Sethi D, Aljunid S, Saperi SB, Zwi $A B$, Hamid $H$, Mustafa AN, Abdullah AH. Comparison of the effectiveness of major trauma services provided by tertiary and secondary hospitals in Malaysia. Journal of Trauma and Acute Care Surgery 2002 Sep 1;53(3):508-16.

10. Shah CM, Ismail IM, Mohsin SS. Ambulance response time and emergency medical dispatcher program: a study in Kelantan, Malaysia. Southeast Asian Journal of Tropical Medicine and Public Health 2008 Nov 1;39(6):1150.

11. Hamzah MS, Ahmad R, Rahman NH, Pardi KW, Jaafar N, Adnan WA, Jaalam K, Jamalullail SM. Ambulance Services at Hospital Universiti Sains Malaysia and Hospital Kota Bharu: A Retrospective Study of Calls. The Malaysian journal of medical sciences: MJMS $2005 \mathrm{Jul} ; 12(2): 34$.

12. Lam SS, Nguyen FN, Ng YY, Lee VP, Wong $\mathrm{TH}$, Fook-Chong SM, Ong ME. Factors affecting the ambulance response times of trauma incidents in Singapore. Accident Analysis \& Prevention 2015 Sep 30; 82:2735.

13. Guppy L, Woollard M. Emergency ambulance services: performance management and review. Prehospital Immediate Care 2000; 4:40-5.

14. Nicholl J, Gilhooley K, Parry G, Turner J, Dixon $\mathrm{S}$. The safety and reliability of priority dispatch systems. Medical Care Research Unit 1996.

15. Turner J, O'Keeffe C, Dixon S, Warren K, Nicholl J. The costs and benefits of changing ambulance service response time performance standards. Sheffield: University of Sheffield. 2006.

16. Campbell JP, Gratton MC, Salomone JA, Watson WA. Ambulance arrival to patient contact: the hidden component of prehospital response time intervals. Annals of emergency medicine 1993 Aug $1 ; 22(8): 1254-7$.

17. Morrison LJ, Angelini MP, Vermeulen MJ, Schwartz B. Measuring the EMS patient access time interval and the impact of responding to high-rise buildings. Prehospital Emergency Care 2005 Jan 1;9(1):14-8.

18. Lateef $F$, Anantharaman V. Delay in EMS response to and the evacuation of patients in high rise buildings in Singapore. Prehospital emergency care 2000 Jan 1;4(4):327-32.

19. Brown LH, Whitney CL, Hunt RC, Addario $M$, Hogue T. Do Warning Lights and Sirens Reduce Ambulance Response Times? Prehospital Emergency Care 2000 Jan 1;4(1):70-4.

20. O'Brien DJ, Price TG, Adams P. The effectiveness of lights and siren use during ambulance transport by paramedics. Prehospital Emergency Care 1999 Jan 1;3(2):127-30.

21. Clawson JJ. Running 'hot' and the case of Sharron Rose. Journal of Emergency Medical Service 1991;16: 11-13.

22. Hunt RC, Brown LH, Cabinum ES, Whitley TW, Prasad NH, Owens CF, Mayo CE. Is ambulance transport time with lights and siren faster than that without? Annals of emergency medicine 1995 Apr $30 ; 25(4): 507-11$.

23. Zainalabidin M, Mohd Idzwan Z, Amiruddin Fairuz M, Syed Hatim M, Tengku Norbanee $\mathrm{TH}$. Validation study of ambulance services form emergency department of HUSM. Malays J Med Sci 2005; 12: 217.

24. Key Performer Indicator PKN. Kementerian Kesihatan Malaysia; 2016. 